\title{
Restriction endonuclease analysis of adenovirus isolates from sporadic and epidemic ocular infections: experience in a clinical laboratory
}

\author{
A. MAHAFZAH* $\dagger \S$ and MARIE L. LANDRY* $\dagger$ \\ "Virology Reference Laboratory, Veterans Administration Medical Center, West Haven and Departments of \\ $\dagger$ Laboratory Medicine and ¥Medicine, Yale University School of Medicine, New Haven, CT, USA
}

\begin{abstract}
Summary. Adenovirus isolates from 52 patients with ocular infection over a 3-year period were typed by restriction endonuclease analysis in a clinical laboratory. The results indicated that adenovirus type 8 was the most common cause of adenovirus eye infection during this period, being responsible for $42(81 \%)$ of the 52 cases. Of 42 adenovirus type 8 isolates, 22 showed variant patterns by restriction endonuclease analysis and required multiple enzyme digests for identification. These isolates were readily identified by neutralisation tests
\end{abstract}

\section{Introduction}

Adenovirus isolates are now commonly identified in clinical laboratories by staining infected cells with group-specific adenovirus monoclonal antibodies. ${ }^{1}$ With the exception of eye isolates, particularly in cases of epidemic keratoconjunctivitis (EKC), type-specific identification is not commonly requested. Conventional typing methods, such as serum neutralisation and haemagglutination inhibition, can be difficult to interpret and time-consuming to perform as well as misleading. ${ }^{2}$ The availability of published restriction endonuclease cleavage patterns of all 41 adenovirus types $^{3}$ now makes it possible for clinical laboratories to identify clinical isolates by restriction endonuclease analysis.

Over a 3-year period, adenoviruses were isolated from eye specimens submitted to the diagnostic laboratory from 11 geographically separate Veterans Administration (VA) facilities. In four of these facilities, outbreaks of EKC occurred and multiple specimens were submitted. Single specimens were submitted from seven other facilities. To evaluate the use of restriction endonuclease analysis for typing adenoviruses in a clinical laboratory, isolates from 52 patients were studied. The results are presented in this report.

\section{Materials and methods}

Virus isolates

Between December 1984 and December 1987,

Received 5 Oct. 1993; accepted 1 Dec. 1993.

$\S$ Present address and address for correspondence: Department of Pathology, Microbiology and Forensic Medicine, Faculty of Medicine, University of Jordan, Amman, Jordan. adenoviruses were isolated from 61 conjunctival swabs from 52 patients with conjunctivitis or keratoconjunctivitis submitted to the Virology Reference Laboratory from 11 different VA Facilities in New York, Connecticut, Idaho, Ohio, Louisiana and Puerto Rico (table I). Detailed clinical or epidemiological data were not available to our laboratory. Multiple isolates from outbreaks of keratoconjunctivitis were obtained from four facilities (table II).

\section{Virus stocks}

Adenovirus isolates were inoculated on to A549 cells (ATCC CCL 185) in roller tubes. Tubes were incubated at $36^{\circ} \mathrm{C}$ until cytopathic effects (CPE) were extensive. Cultures were harvested by three cycles of freezing at $-70^{\circ} \mathrm{C}$ and thawing. Virus suspensions were then stored at $-70^{\circ} \mathrm{C}$ until used.

\section{DNA extraction}

DNA was extracted by the method of Fife, ${ }^{2}$ with modification. Confluent A549 monolayers in $25-\mathrm{cm}^{2}$ flasks were inoculated with adenovirus stocks and incubated at $36^{\circ} \mathrm{C}$ until CPE were extensive. Infected cells were dislodged and transferred to $15-\mathrm{ml}$ conical centrifuge tubes, centrifuged at $400 \mathrm{~g}$ and washed once with phosphate-buffered saline (PBS). The pellet was then resuspended in $300 \mu$ lof Hirt lysis solution (SDS $0.6 \%, 10 \mathrm{~mm}$ EDTA, $\mathrm{pH} 8.0$ ) containing proteinase $\mathrm{K}$ $50 \mu \mathrm{g} / \mathrm{ml}$, and incubated at $37^{\circ} \mathrm{C}$ for $30 \mathrm{~min}$. $\mathrm{NaCl}$ was added to a final concentration of $1 \mathrm{~m}$ and the tubes were incubated at $4^{\circ} \mathrm{C}$ overnight. High mol. wt DNA was pelleted by centrifugation for $4 \mathrm{~min}$ in an Eppendorf microcentrifuge. The supernates were transferred to new tubes and each supernate was treated with $10 \mu \mathrm{g}$ of RNAase A for $30 \mathrm{~min}$ at $37^{\circ} \mathrm{C}$, extracted three 


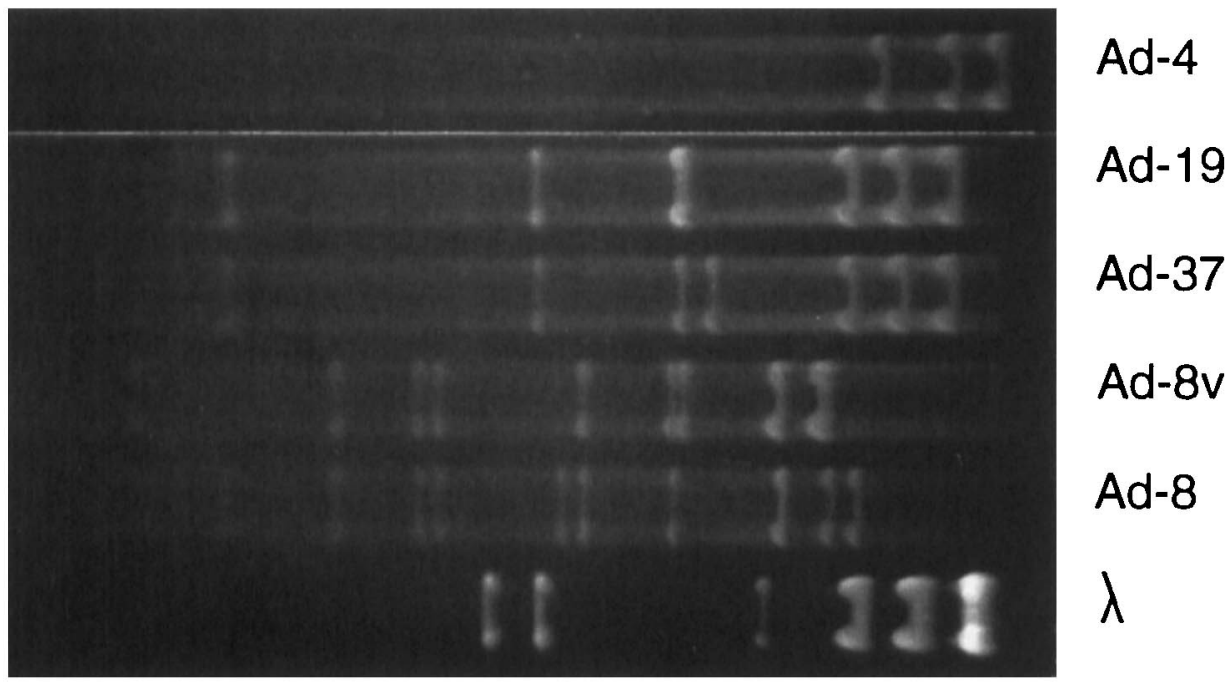

Fig. 1. DNA restriction patterns after HindIII digestion of DNA from Ad-8, an Ad-8 variant (Ad-8v), Ad-37, Ad-19 and Ad-4. A HindIII digest of $\lambda$ phage DNA is included as a reference.

times with phenol-chloroform, then three times with chloroform. The DNA was precipitated with ethanol and then resuspended in $50 \mu 1$ of distilled water.

\section{Restriction endonuclease digestion and electrophoresis}

Samples containing $0.5 \mu \mathrm{g}$ of adenovirus DNA were digested with HindIII, BamHI and SmaI (New England Nuclear) for $2 \mathrm{~h}$ at $37^{\circ} \mathrm{C}$, according to the manufacturer's directions. Reactions were stopped by the addition of one-tenth volume STL buffer (glycerol $50 \%$, SDS $1 \%$, bromophenol blue $0.1 \%$ and $100 \mathrm{~mm}$ EDTA, pH 8.0). Fragments were separated in agarose $0.7 \%$ gels to which ethidium bromide was added at a concentration of $0.5 \mu \mathrm{g} / \mathrm{ml}$. Electrophoresis was performed in Tris-borate (TBE) buffer containing ethidium bromide $0.5 \mu \mathrm{g} / \mathrm{ml}$.

DNA from each isolate was initially digested with HindIII and type assignments were made by comparing the patterns obtained with prototype published patterns. ${ }^{3}$ When patterns obtained could not be matched with those of the prototypes, additional digestions with BamHI and SmaI were made to resolve untyped isolates. Although it was reported that HindIII digestions did not show identical patterns between adenovirus types of the subgenera A, B and $\mathrm{C},{ }^{3}$ its choice for the initial digestion was to some extent arbitrary.

\section{Serum neutralisation tests}

Neutralisation tests were performed to confirm the results of the restriction endonuclease analysis and to determine the identity of those isolates that could not be typed by restriction endonuclease analysis. Antisera to selected adenovirus types were used. The procedure of Hierholzer and Bingham ${ }^{4}$ was followed, with Vero cell cultures in 96-well panels. This neutralisation test measures inhibition of adenovirus toxicity and is read at 5 days by staining the cells with crystal violet.

\section{Results}

HindIII was satisfactory for initial screening of adenovirus isolates, yielding distinctive patterns for types 4, 8, 19 and 37 (fig. 1). Although the prototype strain of adenovirus (Ad)-8 was encountered commonly, two previously unreported variants of Ad-8 (Ad-8v) were equally prevalent in this study. The predominant Ad-8 variant (Ad-8v1) yielded a restriction pattern with $H$ indIII that was distinct from that of the prototype 8 strain. However, with BamHI and Smal, the patterns obtained from both the prototype and the variant strain were identical (fig. 2). The second Ad-8 variant (Ad-8v2) did not yield a restriction pattern characteristic for Ad- 8 with the three enzymes named above, but was clearly type 8 by serum neutralisation tests.

With HindIII, adenovirus types 3 and 16 yielded identical patterns. Thus, analysis with additional enzymes was necessary. In this study, BamHI and SmaI were required to clarify the identity of four isolates as Ad-3.

Over the 3-year period from which isolates were studied, Ad-8 and Ad-8v1 were most commonly identified and they comprised 20 and 19 of 52 isolates respectively. The same Ad-8v1 was isolated in 1986 from specimens submitted from several locations: Bridgeport and West Haven, CT; Albany and Buffalo, NY and New Orleans, LA. Three cases of Ad-8v2 were detected from Buffalo and Northport, NY and West Haven CT (table I). The second most common isolate was Ad-3, with four isolates (8\%). Other types identified were Ad-4, Ad-19 and Ad-37. Two isolates from one patient could not be identified by either restriction endonuclease analysis or serum neutralisation tests. When adenovirus isolates from four outbreaks of EKC were studied, Ad-8 and Ad-8vl comprised 18 each, 36 in total of 43 isolates (table II), and were either the sole of the predominant type in each outbreak. Although two isolates of Ad-19 and 

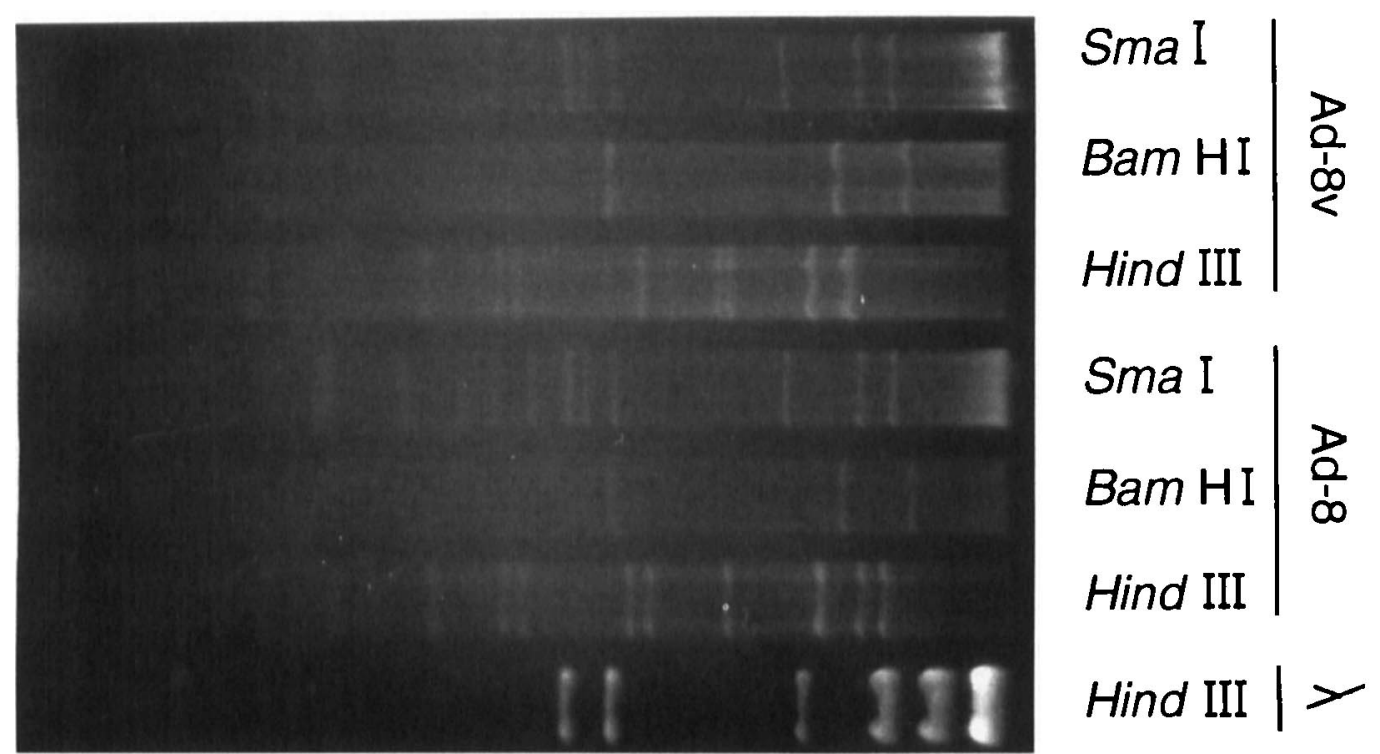

Fig. 2. DNA restriction patterns of Ad-8 and an Ad-8 variant with HindIII, BamHI and SmaI. A HindIII digest of $\lambda$ phage DNA is included as a reference.

Table I. Adenovirus types identified from eye specimens over a 3-year period

\begin{tabular}{lrrrrrrrrr}
\hline & \multirow{3}{*}{$\begin{array}{c}\text { Total number } \\
\text { of } \\
\text { Ysear }\end{array}$} & \multicolumn{8}{c}{ Number of isolates of adenovirus type } \\
\cline { 3 - 10 } & 8 & $8 \mathrm{v} 1$ & $8 \mathrm{v} 2$ & 3 & 4 & 19 & 37 & Untyped \\
\hline 1984 & 7 & 7 & 0 & 0 & 0 & 0 & 0 & 0 & 0 \\
1986 & 42 & 13 & 18 & 2 & 3 & 2 & 2 & 1 & 1 \\
1987 & 3 & 0 & 1 & 1 & 1 & 0 & 0 & 0 & 0 \\
Total & 52 & 20 & 19 & 3 & 4 & 2 & 2 & 1 & 1 \\
\hline
\end{tabular}

$8 \mathrm{v} 1$, Adenovirus type 8 variant $1 ; 8 \mathrm{v} 2$, adenovirus type 8 variant 2 .

one of Ad-37 were detected during this period, these isolates were obtained from samples received as individual specimens and not as part of larger outbreaks of EKC. Multiple types were detected among samples submitted during outbreaks of EKC in Connecticut and New York states. However, the Reference Laboratory was unable to obtain epidemiological data on these patients and could not assess the significance of these findings. Presumably, a number of these patients had community-acquired eye infections. For the Ad- 8 variants and the non-type 8 isolates, an additional isolate was available from each patient from either throat or eye, and restriction endonuclease analysis of the second isolate, as well as serum neutralisation testing, confirmed the initial typing in each case.

\section{Discussion}

During the period 1984-1987, Ad-8 and two previously unreported Ad-8 variants were responsible for most cases of adenovirus eye disease in this study, and were the only viruses to cause epidemics. Ad-19 and Ad-37 were rarely isolated. This is in contrast to recent reports that, since 1973, Ad-19 and then Ad-37 have supplanted Ad-8 as aetiological agents of EKC. . $^{56}$

Despite the frequency of variants for some adenovirus serotypes, ${ }^{7-10} \mathrm{Ad}-8$ has been reported to be fairly stable, with only a limited number of variants. Adenovirus genotypes $8 \mathrm{~A}$ and $8 \mathrm{~B}$ were reported from Japan in $1975-1981 .{ }^{11}$ Genotype $8 \mathrm{C}$ circulated from 1971 to 1974 in an arc from Maryland to Missouri and Alabama, and genotype 8D was isolated in 1975 from Vietnamese refugees in northwest Florida. ${ }^{6}$ With these exceptions, Ad- 8 prototype strain (Trim) has appeared to be genetically stable. In 1986 , the year with the greatest number of EKC isolates in this study, a new Ad-8 variant (Ad-8v1) was found and was equivalent

Table II. Adenovirus types identified from samples submitted during outbreaks of epidemic keratoconjunctivitis $1984-1986$

\begin{tabular}{|c|c|c|c|c|c|c|c|c|}
\hline \multirow{2}{*}{ Year } & \multirow{2}{*}{ Location } & \multirow{2}{*}{$\begin{array}{c}\text { Total number } \\
\text { of } \\
\text { isolates }\end{array}$} & \multicolumn{6}{|c|}{ Number of isolates of adenovirus type } \\
\hline & & & 8 & $8 \mathrm{vl}$ & $8 \mathrm{v} 2$ & 4 & 3 & Untyped \\
\hline 1984 & New York City & 7 & 7 & 0 & 0 & 0 & 0 & 0 \\
\hline 1986 & Connecticut & 10 & 6 & 2 & 1 & 1 & 0 & 0 \\
\hline 1986 & Ohio & 4 & 4 & 0 & 0 & 0 & 0 & 0 \\
\hline 1986 & New York State & 22 & 1 & 16 & 1 & 0 & 3 & 1 \\
\hline Total & & 43 & 18 & 18 & 2 & 1 & 3 & 1 \\
\hline
\end{tabular}


to Ad-8 prototype in frequency of isolation. This variant was isolated from five cities in three states and it was the predominant isolate in the largest outbreak.

Conventional adenovirus typing involves, first, subgrouping by haemagglutination (HA) with rat and monkey red blood cells, followed by haemagglutination inhibition with multiple types of specific antisera. Unfortunately, rat and monkey red blood cells are either not available commercially or are of variable quality, often giving results that are uninterpretable. Neutralisation tests (NT) are labour intensive and, without the benefit of initial subgrouping by HA, theoretically require testing the unknown virus against titred antisera to 41 serotypes. Many laboratories limit NT to serotypes 1-8 or pre-select antisera for testing based on clinical suspicion. In outbreaks of EKC, suspected serotypes are limited, making neutralisation testing more feasible.

Restriction endonuclease analysis has been reported to be more accurate than HI or NT tests. ${ }^{2}$ It also has the potential to trace outbreaks if different genome variants are involved..$^{10}$ The limitations are the need for technical expertise, electrophoresis and photography equipment, and an UV transilluminator. Although routine in a molecular biology laboratory, these may not be available in diagnostic virology laboratories. As molecular techniques become more

\section{References}

1. Mahafzah AM, Landry ML. Evaluation of immunofluorescent reagents, centrifugation, and conventional cultures for the diagnosis of adenovirus infection. Diagn Microbiol Infect Dis $1989 ; 12: 407-411$.

2. Fife KH, Ashley R, Shields AF, Salter D, Meyers JD, Corey L. Comparison of neutralization and DNA restriction enzyme methods for typing clinical isolates of human adenovirus. $J$ Clin Microbiol 1985; 22: 95-100.

3. Adrian T, Wadell G, Hierholzer JC, Wigand R. DNA restriction analysis of adenovirus prototypes 1 to 41 . Arch Virol 1986; 91: 277-290.

4. Hierholzer JC, Bingham PG. Vero Microcultures for adenovirus neutralization tests. $J$ Clin Microbiol 1978; 7: 499506.

5. Kemp MC, Hierholzer JC, Cabradilla CP, Obijeski JF. The changing etiology of epidemic keratoconjunctivitis: antigenic and restriction enzyme analyses of adenovirus types 19 and 37 isolated over a 10 -year period. $J$ Infect Dis 1983 ; 148: 24-33

6. Kemp MC, Hierholzer JC. Three adenovirus type 8 genome types defined by restriction enzyme analysis: prototype routine, ultimately the limiting factor on the use of restriction endonuclease analysis outside the research setting may be the degree of variation within adenovirus genotypes and the frequency with which new variants arise.

In this study, initial identification of the Ad-8v1 required analysis with several endonucleases. Ad-8v2 was not identified after digestion with three enzymes, but required neutralisation testing. Another isolate remained unidentified after multiple digests and serum neutralisation with multiple antisera. Thus, because of the appearance of several adenovirus variants, neutralisation testing was simpler and more straightforward. Although the availability of more comprehensive published catalogues of adenovirus types and their variants would facilitate restriction endonuclease typing by diagnostic laboratories, ${ }^{12}$ the continued emergence of new variants will lead to some confusion.

In conclusion, neutralisation testing with selected antisera based on clinical suspicion of the types involved seems to be more convenient for diagnostic virology laboratories, whereas restriction endonuclease analysis is most useful for epidemiological studies by researchers experienced in its use.

This work was supported in part by Veterans Administration Research Funds. We thank Ivy Medina for her excellent technical assistance.

stability in geographically separated populations. $J$ Clin Microbiol 1986; 23: 469-474.

7. Fife $\mathrm{KH}$, Ashley R, Corey L. Isolation and characterization of six new genome types of human adenovirus types 1 and 2 . J Clin Microbiol 1985; 21 : 20-23.

8. Wadell G, de Jong JC. Restriction endonucleases in identification of a genome type of adenovirus 19 associated with keratoconjunctivitis. Infect Immum 1980; 27: 292-296.

9. Wadell G, Cooney MK, de Costa Linhares A et al. Molecular epidemiology of adenoviruses: global distribution of adenovirus 7 genome types. $J$ Clin Microbiol 1985; 21 : 403-408.

10. Webb DH, Shields AF, Fife KH. Genomic variation of adenovirus type 5 isolates recovered from bone marrow transplant recipients. J Clin Microbiol 1987; 25: 305-308.

11. Fujii SI, Nakozono M, Sawada $\mathrm{H}$ et al. Restriction endonuclease cleavage analysis of adenovirus type 8: two new subtypes from patients with epidemic keratoconjunctivitis in Sapporo, Japan. Jpn J Med Sci Biol 1983; 36: 307-313.

12. Hammond GW, Mauthe G, Joshua J, Hannan CK. Examination of uncommon clinical isolates of human adenoviruses by restriction endonuclease analysis. J Clin Microbiol 1985; 21 : 611-616. 